\title{
XANES OF MANGANESE COORDINATION COMPLEXES
}

\author{
C. CARTIER* ${ }^{*}$ M. VERDAGUER ${ }^{*} * *$, S. MENAGE* , J.J. GIRERD*, \\ J.P. TUCHAGUES ${ }^{* *}$ and B. MABAD ${ }^{* * *}$ \\ *Laboratoire SET, (CNRS - UA 420), Bâtiment 420, \\ F-91405 Orsay Cedex, France \\ * Ecole Normale Supérieure, Le Parc, F-92211 saint-Cloud, France \\ *** Laboratoire de Chimie de Coordination, 205, route de \\ Narbonne, F-31400 Toulouse, France
}

Résumé

Nous avons étudié les spectres Xanes de complexes du Mn(II), Mn(III), Mn(IV), dont la structure et les propriétés électroniques sont parfaitement connues. Nous distinguons trois zones : préseuil, seuil et post-seuil. Nous discutons les variations observées en fonction du degré d'oxydation, de la géométrie et de la nucléarité. Les préseuils présentent une structure que nous comparons à la levée de dégénerescence des orbitales d obtenue par spectroscopie visible et proche infra-rouge. Un déplacement important du seuil est observé lorsque la nucléarité et/ou la géométrie varie. Les différences dans la partie post-seuil, pour le chromophore $\mathrm{Mn}_{\text {(III) }} \mathrm{O}_{6}$ sont liées à la stéréochimie de l'octaedre.

Abstract

XnNES of Mn compounds of known structure and electronic properties [Mn(II), Mn(III), Mn(IV)] is reported. Preedge, Edge and Post-Edge zone are detailed. Dependence on oxidation state, geometry and nuclearity are discussed. Preedge structure is observed and compared with d-orbital splitting obtained from visible NIR spectroscopy. An important Edge shift has been observed with nuclearity and/or geometry change. PostEdge differences due to stereochemistry are observed for the Mn(III) $\mathrm{O}_{6}$ chromofhore.

$\mathrm{Cu}$ and Fe Coordination Chemistry has been much studied for the last ten years. Mn Coordination Chemistry has been much less developped. The same observation can be made for the correlated field of X-ray absorption studies of coordination molecules. We have thus begun X-Ray absorption study of Mn containing molecules. The first objective is fundamental research on X-Ray absorption. The second one is to help biophysicists studying by $\mathrm{X}$-Ray spectroscopy $\mathrm{Mn}$ ions in water evolving photosynthetic apparatus (1). It seems important to asset X-Ray spectroscopy of $\mathrm{Mn}$ in order to be able to extract reliable informations from study of the complicated biological system.

We used very simple Mn containing molecules with well established electronic properties. The studied compounds are listed in Table I together with references to their synthesis and structure.

Experimental conditions

Xanes Data were recorded at LURE on EXAFS I Spectrometer. The monochromator was Si 400 channel cut; the ring storage energy was $1.72 \mathrm{GeV}$ and we used a $0.5 \mathrm{~mm}$ entrance slit. A $8 \mu \mathrm{m} \mathrm{Mn}$ metallic foil was recorded just before each experimental spectrum. We set normalization at the top of the edge and energy origin at the first maximum of the derivative of the metal. Second derivatives were calculated from smoothed experimental curves.

Spectra are given in Fig. 3-4 for compounds $2,3,4,6,7, \underline{9}$.

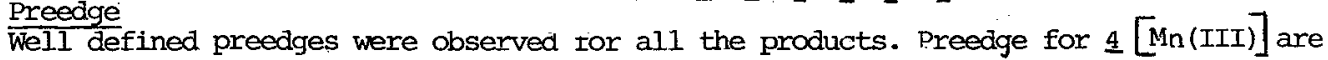
given in Figure 1. For Mn(III) we recorded visible-NIR data on d-d transitions. The structure of the preedge is related in general to the $t_{2 g}{ }^{-e}$ gap. We looked for a cuantitative correspondence between X-Ray data and visible NIR ones using a simple 


\section{Table I : Compounds studied}

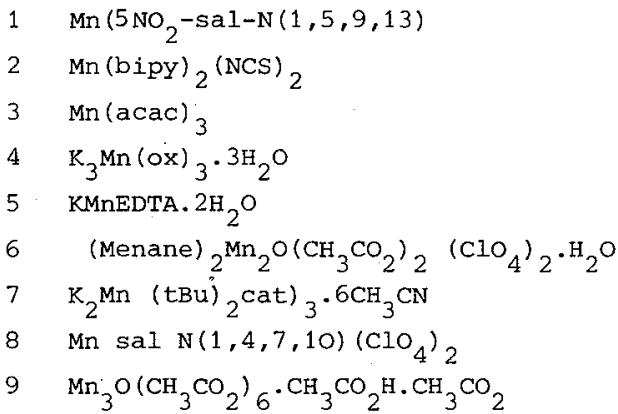

$\begin{array}{lcc}\text { chromophore } & \text { synthesis } & \text { structure } \\ \operatorname{Mn}(\text { II }) \mathrm{N}_{4} \mathrm{O}_{2} & 2 & 2 \\ \operatorname{Mn}(\text { II }) \mathrm{N}_{6} & 3 & 4 \\ \operatorname{Mn}(\text { III }) \mathrm{O}_{6} & 5 & 6 \\ \operatorname{Mn}\left(\text { III } \mathrm{O}_{6}\right. & 7 & 8 \\ \operatorname{Mn}(\text { III }) \mathrm{N}_{2} \mathrm{O}_{4} & 9 & 10 \\ \operatorname{Mn}(\text { III }) \mathrm{N}_{3} \mathrm{O}_{3} & 11 & 11 \\ \operatorname{Mn}(\text { IV }) \mathrm{O}_{6} & 12 & 12 \\ \operatorname{Mn}(\text { IV }) \mathrm{N}_{4} \mathrm{O}_{2} & 13 & 13 \\ \operatorname{Mn}(\text { IV }) \mathrm{O}_{6} & 14 & 14\end{array}$

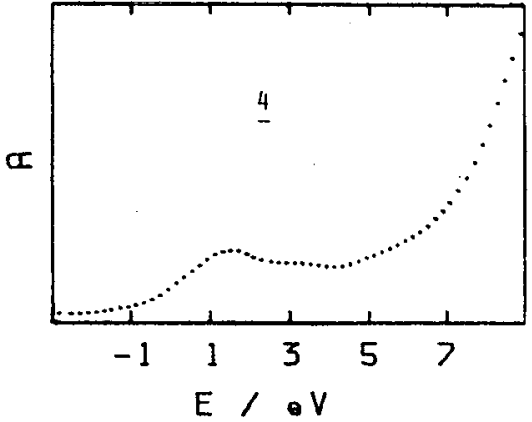

Figure 1 : Preedge for compound 4 .

Figure 2 : Comparison between preedge transitions predicted from visible-NIR data and observed ones in $X-r a y$ aborption for 3,4 and 5 .

monoelectronic picture. Three transitions are expected in X-Ray absorption from the scheme of d molecular orbitals deduced from visible NIR data. This is in agreenent with experiment. But the third transition for compounds 3 and 5 is found systematically at higher energy than predicted : Electron-electron interactions are probably non negligible in the multiplets of the ground and of the excited states in this phenomenon. Comparison between X-Ray data and visible ones are illustrated in Fig. 2.

Edge

In Fig. 3 we compare the spectra of $M($ II), $M(I I I), M(I V)$ with the same nuclearity (here monomers). As expected the absorption is displaced toward higher energy when the oxidation state increases. Surprisingly for compounds 3 [Mn(III)] $6[\mathrm{Mn}$ (III) $-\mathrm{O}-\mathrm{Mn}$ (III)] and $\underline{9}(\mu-\mathrm{O}-\mathrm{Mn}$ (IIII) 3$]$ we found that the edge is displaced at lower energy when one goes from $\underline{3}$ to $\underline{9}$. (See figure 4). Two explanations can be proposed : 1) an effect of distances. The mean radius of the first shell is for $\underline{3}, 1.981$, for 6, 2.083, for 9, 2.193. Thus the 4p orbitals are more destabilized in 3 , than in 6 , than in 9 . 
2. a delocalization effect.

The $4 \mathrm{p}$ excited state would be delocalized in 6 and still more in 9 , thus gaining stabilisation energy.

Post-Edge

Spectra of $\underline{3}$ (Figure 4) and $\underline{4}$ (figure 3) allow to compare $\mathrm{Mn}$ (III) $\mathrm{O}_{6}$ chromophore with different outer shells. The Post-Edge structure is deeply affected by changes is the shells. Multiple scattering occurs in this region and we intend to perform theoretical calculations to find how structural information can be extracted from this part of the XANES spectra on the first coordination sohere and outer ones.

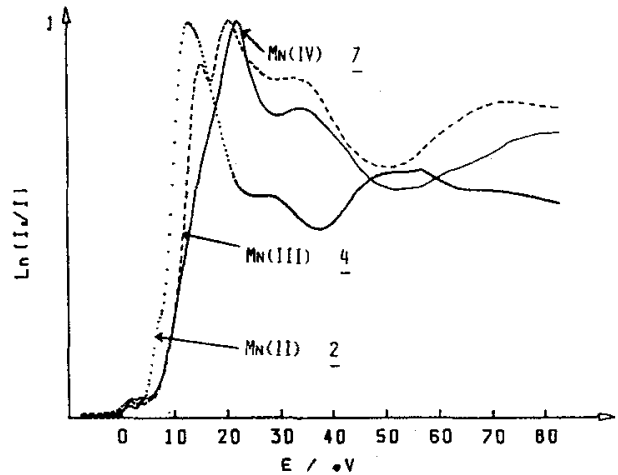

Figure 3 : Comparison of absorption of $\underline{2, \underline{4} \text { and }} \underline{7}$

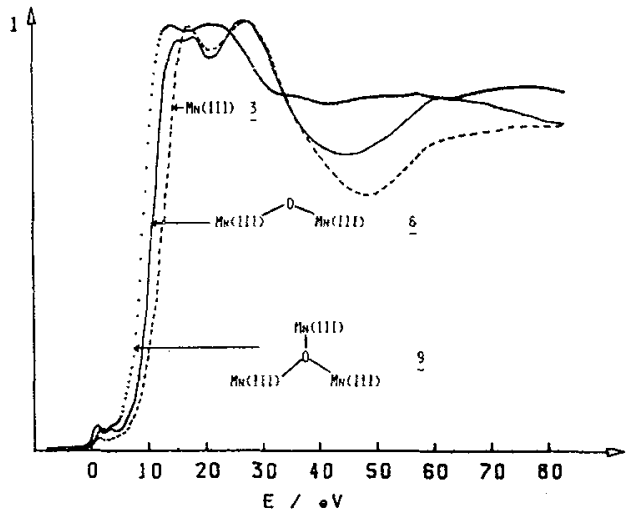

Figure 4 : Spectra of 3,6 and 9 .

\section{Conclusion}

Preedge, Edge and Post-Edge zones of XANES spectra contain many informations since they are sensitive to oxidation and spin states, local geometry (bonds, angles and symmetry), outer geometry and nuclearity. We are currently extending the program to other well characterized Mn systems towards the synthesis of plausible models of biological active sites.

\section{REFERENCES}

1. V.K. Yachandra, R.D. Guiles, A. Mc Dermott, R.D. Britt, S.L. Dexheimer, K. Sauer, M.P. Klein, B.B.A. 1986, 850, 324 .

2. B. Mabad, P. Cassoux, J.P. Tuchagues, D.N. Hendrickson, Inorg. Chem. 1986, 25, 1420.

3. B.V. Dockum, G.A. Eisman, E.H. Witten, W.M. Reiff, Inorg. Chim. Acta, 22, 150.

4. M.V. Veidis, B. Dockum, F.F. Charron Jr, W.M. Reiff, Inorg. Chim. Acta 1981, 53, L 197.

5. G. Pass, H. Sutcliffe, Practical Inorganic Chemistry, Chapman and Hall, London, $2^{\mathrm{e}}$ ed, 1974 .

6. J.P. Fackler Jr, A. Avdeef, Inorg. Chem. 1974, 13, 1864.

7. G. Brauer , Handbook of Preparative Inorganic Chemistry, $2^{e}$ ed, 1965, Academic Press.

8. T. Lis, J. Matuszewski, Acta Crysta. 1980, B 36, 1938

9. A. Yoshino, A. Ouchi, T. Tsunoda, M. Kojima, Can. J. Chem. 1962, 10, 775.

10. J. Stein, J.P. Fackler Jr, G.J. Mc Clune, J.A. Fee, L.T. Chan, Inorg. Chem. $1979,18,3511$.

11. K. Wieghardt, U. Bossek, D. Ventur, J. Weiss, J. Chem. Soc. Chem. Corm. 1985, 347.

12. J.R. Hartman, B.M. Foxman, S.R. Cooper, Inorg. Chem. 1984, 23, 1381-1387.

13. J.P. Tuchagues, to be published.

14. I.W. Hessel, C. Romers, Rec. Trav. Pays-Bas 1969, 88, 545. 